\title{
Motivasi, Disiplin Kerja Dan Kompensasi Terhadap Produktifitas Kerja
}

\author{
Edi Siregar* \\ *Dosen Tetap Program S1 Jurusan Manajemen Fakultas Ekonomi Universitas Satya Negara Indonesia \\ edisiregarusi@gmail.com
}

\begin{abstract}
The purpose of this research is to know the influence of motivation, work discipline and compensation to work productivity. The analytical method used descriptive analysis. The sample of this research is 55 people by using multiple linear regression analysis tools. The result of this research show that partially motivation have significant effect to employee work productivity with $t$ count $>t$ table that is 2,027 > 2,008, work discipline has no significant effect on employee productivity with tcount $<t$ table is $-0.657<2,008$, and compensation has significant effect on productivity work with a value of $t$ count $>t$ table that is 4,075 $>2,008$. While simultaneously show that motivation, work discipline and compensation effect simultaneously to work productivity of employees of PT. BCA General Insurance with F count $>F$ table is 13,334 > 2,786 .
\end{abstract}

Keywords: Motivation, Work Discipline, Compensation, Work Productivity.

\section{Pendahuluan}

PT. Asuransi Umum BCA merupakan perusahaan asuransi yang diiringi penyempurnaan sistem dan peningkatan kualitas SDM dengan keahlian semangat baru yang siap berkompetisi secara confident dan produktif. Namun untuk motivasi kerja masih sangat kurang sehingga hasil kerja tidak memuaskan atau di bawah standar. PT. Asuransi Umum BCA juga perlu pembenahan untuk memotivasi karyawan agar lebih giat lagi bekerja agar perusahaan asuransi ini dapat bersaing dengan perusahaan asuransi lain sehingga dapat menjadi perusahaan asuransi pilihan utama dan berperan sebagai pilar penting industri perasuransian. Sedangkan untuk disiplin kerja masih saja ada karyawan yang datang terlambat. Sementara kompensasi yang diberikan kepada para karyawan masih kurang berkembang, karena kompensasi dalam bentuk gaji karyawan masih tergolong rendah untuk dapat meningkatkan produktivitas karyawan PT. Asuransi Umum BCA.

Meningkatkan produktivitas kerja karyawan dapat dipengaruhi oleh beberapa faktor atau variabel, antara lain variabel: motivasi, disiplin kerja dan kompensasi. Produktivitas sebagai suatu perbandingan antara hasil yang dicapai dengan keseluruhan daya atau faktor produksi yang digunakan suatu organisasi atau perusahaan. Dari ketiga variabel tersebut dapat diasumsikan bahwa untuk meningkatkan produktivitas kerja yang pertama dipengaruhi oleh faktor motivasi.

Motivasi adalah proses yang menjelaskan intensitas individu, arah, dan ketekunan usaha terhadap pencapaian tujuan. Variabel kedua adalah disiplin kerja. Disiplin kerja yang baik karyawan mencerminkan tanggungjawab seorang karyawan terhadap pekerjaan yang diberikan. Faktor atau variabel ketiga dari produktivitas karyawan diasumsikan dipengaruhi variabel kompensasi. Kompensasi adalah sesuatu yang diterima karyawan sebagai pengganti kontribusi jasa mereka pada perusahaan. Para karyawan cenderung membedakan antara kompensasi dengan upah, gaji, insentif, dan ghainsharing.

Dari gambaran penjelasan di atas, maka penulis memandang penting dilakukan penelitian untuk melihat pengaruh dari ketiga variabel bebas tersebut terhadap produktivitas kerja karyawan. Melalui data primer dari para karyawan sehingga diperoleh suatu hasil penelitian yang digunakan 
secara umum oleh pengusaha atau perusahaan asuransi dan secara khusus bermanfaat bagi PT. Asuransi Umum BCA Cabang Veteran Jakarta Selatan. Namun untuk terarah dan lebih baik penelitian merumuskan permasalahan agar dapat mencapai tujuan penelitian yang efektif dan efisien.

\section{Rumusan Masalah}

1. Apakah terdapat pengaruh motivasi terhadap produktivitas kerja karyawan PT. Asuransi Umum BCA Cabang Veteran Jakarta Selatan?

2. Apakah terdapat pengaruh disiplin kerja terhadap produktivitas kerja karyawan PT. Asuransi Umum BCA Cabang Veteran Jakarta Selatan?

3. Apakah terdapat pengaruh kompensasi terhadap produktivitas kerja karyawan PT. Asuransi Umum BCA Cabang Veteran Jakarta Selatan?

4. Apakah motivasi, disiplin kerja dan kompensasi secara bersama-sama berpengaruh terhadap produktivitas kerja karyawan PT.Asuransi Umum BCA Cabang Veteran Jakarta Selatan?

\section{Landasan Teori}

Setiap organisasi profit maupun non profit sudah pasti berharap bahkan menuntut produktivitas kerja dari setiap pekerja untuk mencapai tujuan bersama yang dicita-citakan. Rumindor (2012:270) menyatakan bahwa produktivitas sebagai perbandingan antara hasil yang dicapai dengan keseluruhan daya atau faktor produksi yang digunakan. Produktivitas adalah kemampuan memperoleh manfaat sebesar-besarnya dari sarana dan prasarana yang tersedia dengan menghasilkan (output) bahkan kalau mungkin yang optimal.

Untuk meningkatkan produktivitas kerja karyawan tidak terlepas bahkan banyak penelitian menyatakan dipengaruhi motivasi kejra karyawan. Menurut Lyman W. Porter dalam Emron Edison (2016:238) mengatakan bahwa motivasi adalah proses yang menjelaskan intensitas individu, arah, dan ketekunan usaha terhadap pencapaian tujuan. Pengertian motivasi menurut Richard M. Steers dalam Sedarmayanti (2013) lebih spesifik mengatakan bahwa; motivasi adalah kekuatan kecenderungan seorang individu melibatkan diri dalam kegiatan yang berarahkan sasaran dalam pekerjaan. Ini bukan perasaan senang yang relatif terhadap hasil berbagai pekerjaan sebagaimana halnya kepuasan, tetapi lebih berupa perasaan sedia/ rela bekerja untuk mencapai tujuan pekerjaan.

Meningkatkan produktivitas kerja karyawan bukan hanya dibutuhkan motivasi kerja bahkan banyak penelitian menyatakan dipengaruhi juga dengan disiplin kerja karyawan. Menurut Rivai (2011) bahwa; disiplin kerja adalah suatu alat yang dipergunakan para manajer untuk berkomunikasi dengan karyawan agar mereka bersedia untuk mengubah suatu perilaku serta sebagai suatu upaya untuk meningkatkan kesadaran dan kesedian seorang dalam memenuhi segala peraturan perusahaan. Menurut Nitisemito (2011) menyatakan bahwa disiplin kerja yang baik mencerminkan besar rasa tanggung jawab seorang karyawan terhadap pekerjaan yang diberikan kepadanya.

Dalam upaya meningkatkan produktivitas kerja karyawan bukan hanya motivasi dan disiplin kerja karyawan tetapi juga dipengaruhi dengan kompensari yang diterima karyawan. Menurut Emron Edison dkk (2016), kompensasi adalah sesuatu yang diterima karyawan atas jasa yang mereka sumbangkan pada pekerjaannya. Karyawan menyumbangkan yang berharga, baik tenaga maupun pengetahuan yang dimiliki. Sesuatu yang berharga bagi karyawan adalah pengetahuan dan keterampilan yang dimiliki dijadikan sebagai dasar dalam menuntut hak sebagai pekerja (Wilson Bangun, 2012). Menurut Werther dan Davis dalam Lijan Poltak (2016) menyatakan kompensasi merupakan sesuatu yang diterima pegawai sebagai penukar atas kontribusi jasa mereka bagi organisasi. Apabila dikelola dengan baik maka kompensasi membantu organisasi mencapai tujuan dan memperoleh, memelihara, dan menjaga pegawai dengan baik. Menurut Melayu S.P. Hasibuan (2011:121) tujuan pemberian kompensasi (balas jasa) antara lain: 
1. Memperoleh SDM yang Berkualitas

2. Mempertahankan Karyawan yang Ada

3. Menjamin Keadilan

4. Penghargaan terhadap Perilaku yang Diinginkan

5. Mengendalikan Biaya, Mengikuti Aturan Hukum

6. Memfasilitasi Pengertian

7. Meningkatkan efisiensi Administrasi.

\section{Kerangka Penelitian}

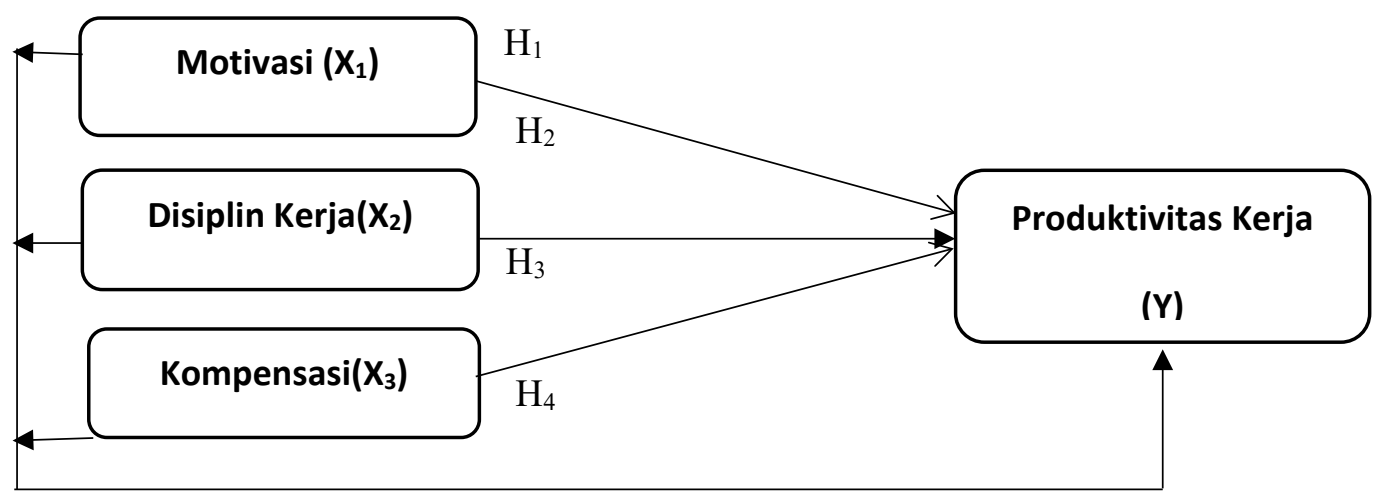

Gambar 2.1

Kerangka Penelitian

\section{Metode Penelitian}

Menjadi sumber data primer dari sampel dalam penelitian ini adalah seluruh karyawan PT. Asuransi Umum BCA Cabang Veteran Jakarta Selatan berjumlah 55 (lima puluh lima) orang karyawan tetap dengan pendidikan terakhir sarjana strata satu (S1) dan tidak mengikutsertakan Kepala Pimpinan Cabang sebagai responden. Oleh karena seluruh karyawan tetap PT. Asuransi Umum BCA yang berjumlah keseluruhan 55 (lima puluh lima) orang juga sebagai populasi penelitian ini dibawah 100 orang, maka peneliti menggunakan metode sensus dalam pengambilan data primer dari populasi yang menjadi sampel. Adapun metode pengambilan data yang digunakan dalam penelitian ini adalah:

1. Kuesioner

2. Observasi

3. Studi Pustaka

\section{Uji Reliabilitas}

\begin{tabular}{|l|l|l|l|l|}
\hline Variabel & $\begin{array}{l}\text { Cronbach's } \\
\text { Alpha }\end{array}$ & Kondisi & $\begin{array}{l}\text { Cronbach's } \\
\text { Alpha }\end{array}$ & Status \\
\hline Motivasi & 0,752 & $>$ & 0,60 & Reliabel \\
\hline Disiplin Kerja & 0,747 & $>$ & 0,60 & Reliabel \\
\hline Kompensasi & 0,745 & $>$ & 0,60 & Reliabel \\
\hline Produktivitas Kerja & 0,747 & $>$ & 0,60 & Reliabel \\
\hline
\end{tabular}


Berdasarkan pengujian pada tabel uji reliabilitas di atas dapat diketahui bahwa semua variabel mempunyai Cronbach Alpha > 0,60 (60\%), maka dapat disimpulkan bahwa keseluruhan variabel dalam penelitian ini adalah reliabel.

\section{Uji Normalitas}

\begin{tabular}{|c|c|c|c|c|c|}
\hline \multicolumn{6}{|c|}{ One-Sample Kolmogorov-Smirnov Test } \\
\hline & & MOTIVASI & $\begin{array}{c}\text { DISIPLIN } \\
\text { KERJA }\end{array}$ & KOMPENSASI & $\begin{array}{c}\text { PRODUKTIVITAS } \\
\text { KERJA }\end{array}$ \\
\hline \multirow[t]{2}{*}{$\begin{array}{c}\mathrm{N} \\
\text { Normal Parameters }^{\mathrm{a}, \mathrm{b}}\end{array}$} & Mean & $\begin{array}{c}55 \\
46.64\end{array}$ & $\begin{array}{c}55 \\
48.93\end{array}$ & $\begin{array}{c}55 \\
45.71\end{array}$ & $\begin{array}{c}55 \\
54.22\end{array}$ \\
\hline & $\begin{array}{c}\text { Std. } \\
\text { Deviation }\end{array}$ & 5.282 & 6.517 & 6.011 & 5.231 \\
\hline \multirow{3}{*}{$\begin{array}{l}\text { Most Extreme } \\
\text { Differences }\end{array}$} & Absolute & .118 & .146 & .147 & .155 \\
\hline & Positive & .071 & .146 & .147 & .155 \\
\hline & Negative & -.118 & -.093 & -.101 & -.117 \\
\hline \multirow{2}{*}{\multicolumn{2}{|c|}{$\begin{array}{c}\text { Test Statistic } \\
\text { Asymp. Sig. (2-tailed) }\end{array}$}} & .118 & .146 & .147 & .155 \\
\hline & & $.053^{\mathrm{c}}$ & $.005^{\mathrm{c}}$ & $.005^{\mathrm{c}}$ & $.002^{\mathrm{c}}$ \\
\hline
\end{tabular}

\section{Uji Heteroskeditas}

Berdasarkan grafik uji Heteroskedastisitas titik-titik menyebar secara acak, tidak membentuk pola tertentu dengan jelas, serta tersebar baik di atas maupun di bawah angka 0 (nol) pada sumbu Y. Jadi model regresi yang diajukan dapat dilanjutkan untuk dianalisis karena asumsi klasik yang meliputinya tidak terjadi gejala heteroskedastisitas. Hal ini berarti model regresi layak digunakan.

\section{Uji Multikolinearitas}

\begin{tabular}{|c|c|c|c|}
\hline & \multirow[b]{2}{*}{ Model } & \multicolumn{2}{|c|}{ Collinearity Statistics } \\
\hline & & Tolerance & VIF \\
\hline \multirow[t]{4}{*}{1} & (Constant) & & \\
\hline & Motivasi & .853 & 1.173 \\
\hline & disiplin_kerja & .579 & 1.728 \\
\hline & Kompensasi & .517 & 1.933 \\
\hline
\end{tabular}

Dari hasil tersebut di atas diketahui bahwa model regresi tidak terjadi gejala multikolinearitas, karena nilai tolerance yang ditunjukan lebih besar dari 0.10 dan nilai VIF lebih kecil dari 10. Jadi model regresi yang diajukan dapat dilanjutkan untuk dianalisis karena asumsi klasik ada gejala multikolinearitas antar variabel bebas.

\section{Uji Autokorelasi}

\begin{tabular}{|c|c|c|c|c|c|}
\hline Model & $\mathrm{R}$ & R Square & $\begin{array}{c}\text { Adjusted R } \\
\text { Square }\end{array}$ & $\begin{array}{c}\text { Std. Error of the } \\
\text { Estimate }\end{array}$ & Durbin-Watson \\
\hline 1 & $.664^{\mathrm{a}}$ & .441 & .408 & 4.023 & 1.793 \\
\hline
\end{tabular}

Nilai dU dan dL dapat diperoleh dari tabel statistik Durbin-Watson. Dengan menggunakan signifikansi $5 \%$ dan banyaknya sampel (n) adalah 55 serta variabel independent 
(Motivasi, Disiplin Kerja, Kompensasi) ada $3(\mathrm{k}=3)$. Model summary di atas menunjukkan nilai $\mathrm{DW}=1.793$ Selanjutnya berdasarkan tabel statistik Durbin-Watson diperoleh nilai $\mathrm{dU}=1,6815$ dan $\mathrm{dL}=1$, 4523. Karena nilai DW hitung $(1,793)$ lebih besar dari DW tabel atau 1, 6815<1,793 $<2,318$ dapat disimpulkan pula $\mathrm{dU}<\mathrm{DW}<4$-dU, maka tidak terjadi autokorelasi sehingga pengolahan data dapat dilanjutkan.

\section{Uji Linier Berganda}

\begin{tabular}{|c|c|c|c|c|c|c|c|c|}
\hline & \multirow[b]{2}{*}{ Model } & \multicolumn{2}{|c|}{$\begin{array}{c}\text { Unstandardized } \\
\text { Coefficients }\end{array}$} & \multirow{2}{*}{$\begin{array}{c}\begin{array}{c}\text { Standardize } \\
\mathrm{d}\end{array} \\
\text { Coefficients }\end{array}$} & \multirow[b]{2}{*}{$\mathrm{t}$} & \multirow[b]{2}{*}{ Sig. } & \multicolumn{2}{|c|}{$\begin{array}{c}\text { Collinearity } \\
\text { Statistics }\end{array}$} \\
\hline & & B & Std. Error & & & & Tolerance & VIF \\
\hline \multirow[t]{4}{*}{1} & (Constant) & 22.565 & 5.516 & & 4.091 & .000 & & \\
\hline & Motivasi & .228 & .112 & .230 & 2.027 & .048 & .853 & 1.173 \\
\hline & disiplin_kerja & -.054 & .082 & -.091 & -.657 & .514 & .579 & 1.728 \\
\hline & Kompensasi & .517 & .127 & .594 & 4.075 & .000 & .517 & 1.933 \\
\hline
\end{tabular}

Persamaan regresinya sebagai berikut:

$$
\mathrm{Y}=\mathrm{a}+\mathrm{b}_{1} \mathrm{X}_{1}+\mathrm{b}_{2} \mathrm{X}_{2}+\mathrm{b}_{3} \mathrm{X}_{3}
$$

$Y=22,565+0,228 X_{1}+(-0,054) X_{2}+0,517 X_{3}$

Persamaan regresi di atas dapat dijelaskan sebagai berikut:

a. Nilai konstanta (a) sebesar 22,565. Hal ini berarti jika Motivasi $\left(\mathrm{X}_{1}\right)$, Disiplin Kerja $\left(\mathrm{X}_{2}\right)$, Kompensasi $\left(\mathrm{X}_{3}\right)$, nilainya 0 , maka Produktivitas Kerja bernilai positif yaitu sebesar 22,565 .

b. Nilai koefisien regresi variabel motivasi $\left(X_{1}\right)$ bernilai positif yakni 0,228 . Hal ini dapat diartikan bahwa setiap peningkatan motivasi kerja sebanyak 1 satuan, maka akan berpengaruh terhadap produktivitas kerja dengan asumsi variabel independen lainnya tetap.

c. Nilai koefisien regresi variabel disiplin kerja $\left(\mathrm{X}_{2}\right)$ bernilai negatif yakni $-0,054$. Hal ini dapat diartikan bahwa setiap peningkatan disiplin kerja sebesar 1 satuan, maka akan menurunkan produktivitas kerja sebesar 0,054 satuan. Koefisien bernilai negatif artinya terjadi hubungan negatif antara disiplin kerja dengan produktivitas kerja, semakin naik disiplin kerja maka semakin menurun produktivitas kerja.

d. Nilai koefisien regresi variabel kompensasi $\left(\mathrm{X}_{3}\right)$ bernilai positif yakni 0,517 . Hal ini diartikan bahwa setiap peningkatan kompensasi sebesar 1 satuan, mengalami peningkatan produktivitas kerja dengan asumsi variabel independen lainnya tetap.

\section{Uji T}

\begin{tabular}{|l|c|l|c|c|l|}
\hline \multicolumn{1}{|c|}{ Variabel Bebas } & $\mathbf{t}_{\text {hitung }}$ & \multicolumn{1}{c|}{ Kondisi } & $\mathbf{t}_{\text {tabel }}$ & Sig & \multicolumn{1}{c|}{ Keterangan } \\
\hline Motivasi & 2,027 & $>$ & 2,008 & 0,048 & H0 ditolak \\
\hline Disiplin Kerja & $-0,657$ & $<$ & 2,008 & 0,514 & H0 diterima \\
\hline & & & & & \\
Kompensasi & 4,075 & $>$ & 2,008 & 0,000 & H0 ditolak \\
\hline
\end{tabular}

Terlihat pada kolom coefficient terdapat nilai sig 0,048 nilai sig lebih kecil dari nilai probabilitas 0,05 , atau $0,048<0,05$. Variabel motivasi $\left(\mathrm{X}_{1}\right)$ mempunyai t-hitung yakni 2,027 
dengan $t_{\text {-tabel }}$ 2,008. Jadi $t_{\text {-hitung }}>\mathrm{t}_{\text {-tabel }}$ dapat disimpulkan bahwa variabel motivasi $\left(\mathrm{X}_{1}\right)$ memiliki kontribusi terhadap produktivitas kerja (Y). Nilai t positif menunjukkan bahwa variabel motivasi $\left(\mathrm{X}_{1}\right)$ mempunyai hubungan yang searah dengan produktivitas kerja $(\mathrm{Y})$, yang berarti $\mathrm{H}_{\mathrm{ol}}$ ditolak $\mathrm{H}_{\mathrm{a} 1}$ diterima. Jadi dapat disimpulkan bahwa motivasi memiliki pengaruh positif yang signifikan secara parsial terhadap produktivitas kerja.

Tidak ada pengaruh dan tidak signifikan disiplin kerja terhadap produktivitas kerja. Berdasarkan tabel bahwa $\mathrm{t}$-hitung $-0,657<\mathrm{t}$-tabel 2,008 dan signifikan $0,514>0,05$ dengan demikian Ho ditolak dan Ha diterima, sehingga secara parsial tidak terdapat pengaruh dan tidak signifikan disiplin kerja terhadap produktivitas kerja.

Terlihat pada kolom coefficient terdapat nilai sig 0,000 nilai sig lebih kecil dari nilai probabilitas 0,05 , atau $0,000<0,05$. Variabel kompensasi $\left(\mathrm{X}_{3}\right)$ mempunyai t-hitung yakni 4,075 dengan $t_{\text {-tabel }}$ 2,008. Jadi $t_{\text {-hitung }}>\mathrm{t}_{\text {-tabel }}$ dapat disimpulkan bahwa variabel kompensasi $\left(\mathrm{X}_{3}\right)$ memiliki kontribusi terhadap produktivitas kerja (Y). Nilai t positif menunjukkan bahwa variabel kompensasi $\left(\mathrm{X}_{3}\right)$ mempunyai hubungan yang searah dengan produktivitas kerja $(\mathrm{Y})$, yang berarti $\mathrm{H}_{\mathrm{o} 1}$ ditolak $\mathrm{H}_{\mathrm{a} 1}$ diterima. Jadi dapat disimpulkan bahwa kompensasi memiliki pengaruh positif yang signifikan secara parsial terhadap produktivitas kerja.

\section{Uji F}

\begin{tabular}{|c|c|c|c|c|c|c|}
\hline & Model & Sum of Squares & $\mathrm{df}$ & Mean Square & $\mathrm{F}$ & Sig. \\
\hline \multirow[t]{3}{*}{1} & Regression & 649.427 & 3 & \multirow{3}{*}{$\begin{array}{r}216.476 \\
16.234\end{array}$} & \multirow[t]{3}{*}{13.334} & \multirow[t]{3}{*}{$.000^{\mathrm{b}}$} \\
\hline & Residual & 827.955 & 51 & & & \\
\hline & Total & 1477.382 & 54 & & & \\
\hline
\end{tabular}

Berdasarkan hasil uji ANOVA atau $\mathrm{F}$ test pada Tabel 4.11 didapatkan $\mathrm{F}_{\text {hitungsebesar }}$ 13,334. Dari hasil uji koefisien regresi secara bersama-sama di atas, diperoleh signifikansi 0,000 . Karena $\mathrm{F}_{\text {hitung }}>\mathrm{F}_{\text {table }}(13,334>2,786)$ dan tingkat signifikansi $0,000<0,05$ sehingga $\mathrm{H}_{0}$ ditolak dan $\mathrm{H}_{\mathrm{a}}$ diterima. Artinya, variabel motivasi, disiplin kerja dan kompensasi berpengaruh secara simultan terhadap produktivitas kerja.

Koefisien Determinasi $\left(\mathbf{R}^{2}\right)$

\begin{tabular}{|r|r|r|r|r|}
\hline \multicolumn{1}{|c|}{ Model } & R & \multicolumn{1}{c|}{ R Square } & Adjusted R Square & Std. Error of the Estimate \\
\hline 1 & $.664^{\mathrm{a}}$ & .441 & .408 & 4.023 \\
\hline
\end{tabular}

a. Predictors: (Constant), KOMPENSASI, MOTIVASI, DISIPLIN_KERJA

b. Dependent Variable: PRODUKTIVITAS_KERJA

Karena variabel bebas lebih dari dua (motivasi, disiplin kerja dan kompensasi) maka disarankan menggunakan Adjusted $\boldsymbol{R}$ Square sehingga dalam hal ini berarti 0,408 atau sebesar 40,8\% menunjukan persentase sumbangan pengaruh variabel independen (motivasi, disiplin kerja dan kompensasi) terhadap variabel dependen (produktivitas kerja). Sedangkan sisanya sebesar $57,6 \%(100 \%-40,8 \%=59,2 \%)$ dipengaruhi atau dijelaskan oleh variabel lain di luar penelitian.

\section{Hasil dan Pembahasan}

Hasil penelitian mengenai motivasi, disiplin kerja dan kompensasi terhadap produktivitas kerja karyawan PT. Asuransi Umum BCA Cabang Veteran Jakarta Selatan dapat dibuat pembahasan sebagai berikut: Berdasarkan hasil penelitian di atas dapat dikatakan bahwa variabel 
motivasi mempengaruhi variabel produktivitas kerja dengan Nilai t-hitung positif untuk variabel motivasi 2,027 lebih besar dari nilai t-tabel sebesar 2,008 dengan tingkat signifikansi 0,048<0,05. Artinya dapat disimpulkan bahwa $\mathrm{H}_{\mathrm{a}}$ diterima yang berarti variabel motivasi berpengaruh positif yang signifikan secara parsial terhadap produktivitas kerja pada karyawan PT. Asuransi Umum BCA.

Hasil penelitian ini sesuai dengan teori Menurut Lyman W. Porter dalam Emron Edison dkk (2016:238) mengatakan bahwa motivasi adalah proses yang menjelaskan intensitas individu, arah, dan ketekunan usaha terhadap pencapaian tujuan. Hasil penelitian ini juga sesuai dengan penelitian yang dilakukan oleh oleh Sofian (2009) bahwa motivasi berpengaruh positif dan signifikan terhadap produktivitas kerja karyawan.

Berdasarkan hasil penelitian di atas dapat dikatakan bahwa disiplin kerja tidak berpengaruh signifikan terhadap produktivitas kerja. Dengan nilai t-hitung negatif untuk variabel disiplin kerja -0,657 lebih besar dari nilai t-tabel sebesar 2,008 dengan tingkat signifikansi $-0,514<$ 0,05 . yang berarti bahwa hipotesis dalam penelitian ini Ho ditolak dan Ha diterima, sehingga secara parsial tidak terdapat pengaruh dan tidak signifikan disiplin kerja terhadap produktivitas kerja pada karyawan PT. Asuransi Umum BCA.

Menurut Handoko (2016) dalam Lijan Poltak menyatakan bahwa disiplin kerja adalah kesediaan seseorang yang timbul dengan kesadaran sendiri untuk mengikuti peraturan-peraturan yang berlaku dalam organisasi. Hasil penelitian ini tidak sesuai dengan penelitian sebelumnya yang dilakukan oleh Pustika Dewi (2012) bahwa disiplin kerja berpengaruh positif dan signifikan terhadap produktivitas kerja.

Berdasarkan hasil penelitian di atas dapat dikatakan bahwa variabel kompensasi mempengaruhi variabel produktivitas kerja dengan Nilai t-hitung positif untuk variabel kompensasi 4,075 lebih besar dari nilai $t$-tabel sebesar 2,008 dengan tingkat signifikansi $0,000<0,05$. Artinya dapat disimpulkan bahwa $\mathrm{H}_{\mathrm{a}}$ diterima yang berarti variabel kompensasi berpengaruh positif yang signifikan secara parsial terhadap produktivitas kerja pada PT. Asuransi Umum BCA.

Hasil penelitian ini sesuai dengan teori menurut Emron Edison dkk (2016) Kompensasi adalah sesuatu yang diterima karyawan atas jasa yang mereka sumbangkan pada pekerjaannya. Mereka menyumbangkan yang menurut mereka berharga, baik tenaga maupun pengetahuan yang dimiliki. Sesuatu yang berharga bagi karyawan adalah pengetahuan dan keterampilan yang dimiliki dijadikan sebagai dasar dalam menuntut hak sebagai pekerja.

Hasil penelitian ini juga sesuai dengan penelitian yang dilakukan oleh Sis Wartono (2014) bahwa kompensasi berpengaruh positif dan signifikan terhadap produktivitas kerja karyawan. Karena kompensasi merupakan salah satu cara yang dapat diberikan perusahaan berupa imbalan kepada karyawan.

Berdasarkan hasil uji ANOVA di atas dapat dilihat bahwa nilai $\mathrm{F}_{\text {-hitung }}$ sebesar 13,334 dengan nilai probabilitas (sig) $=0,000$. Nilai $\mathrm{F}_{\text {-hitung }}$ 13,334 $>\mathrm{F}_{\text {-tabel }}$ 2,786. Dan nilai sig lebih kecil dari nilai probabilitas 0,05 atau $0,000<0,05$. maka $\mathrm{H}_{\mathrm{o}}$ ditolak dan $\mathrm{H}_{\mathrm{a}}$ diterima, berarti secara bersama-sama variabel motivasi $\left(\mathrm{X}_{1}\right)$, disiplin kerja $\left(\mathrm{X}_{2}\right)$ dan kompensasi $\left(\mathrm{X}_{3}\right)$ berpengaruh positif yang signifikan secara simultan terhadap produktivitas kerja (Y) pada PT. Asuransi Umum BCA.

\section{Kesimpulan dan Saran}

Penelitian ini menguji pengaruh variabel motivasi, disiplin kerja dan kompensasi terhadap produktivitas kerja karyawan PT. Asuransi Umum BCA. Berdasarkan hasil analisis penelitian dalam pembahasan Bab IV, maka dapat ditarik kesimpulan bahwa terdapat pengaruh motivasi terhadap produktivitas kerja 2,027 dengan tabel 2,008. Tidak terdapat pengaruh disiplin

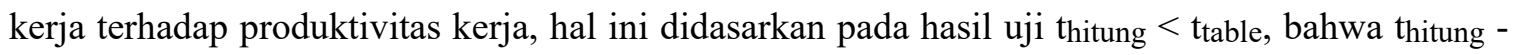
$0,657<$ tabel 2,008. Terdapat pengaruh kompensasi terhadap produktivitas kerja, hal ini didasarkan pada hasil uji thitung $>t_{\text {tabel. }}$ thitung yakni 4,075 dengan tabel 2,008. Jadi thitung $>t_{\text {tabel. }}$ 
Terdapat pengaruh motivasi, disiplin kerja dan kompensasi terhadap produktivitas kerja, hal ini didasarkan pada hasil uji Fhitung $>$ F table y $(13,334>2,786)$.

Berdasarkan penelitian yang telah dilakukan maka saran yang dapat diberikan kepada perusahaan agar lebih ditingkatkan lagi pemberian motivasi seperti memberikan jenjang karir kepada karyawan yang berprestasi, sehingga karyawan lebih semangat bekerja untuk mendapatkan jabatan yang lebih baik dari sebelumnya. Perusahaan harus tegas dalam memberikan sanksi saat karyawan datang terlambat dan tidak masuk kerja sehingga dapat meningkatkan produktivitas kerja. Dalam pemberian kompensasi kepada karyawan lebih ditingkatkan lagi pemberian insentif dan bonus sehingga meningkatkan poduktivitas kerja.

\section{Daftar Pustaka}

Alex S. Nitisemo. Manajemen Personalia. Jakarta: Gharia Indonesia, 2009.

Bangun Wilson. Manajemen Sumber Daya Manusia. Cetakan Kesatu. Jakarta: Erlangga, 2012.

Emron Edison, dkk. Manajemen Sumber Daya Manusia Dalam Strategi Dan Perubahan. Bandung: Alfabeta, 2016.

Ghozali, Imam. Aplikasi Analisis Multivariate dengan Program SPSS.Semarang: BP Universitas Diponegoro, 2005.

Hasibuan, Melayu. S.P. Manajemen Sumber Daya Manusia. Jakarta: Bumi Aksara

Iis Pustika, Dewi. Pengaruh Disiplin Kerja Terhadap Produktivitas Kerja Karyawan. Jurnal dipublikasikan. Surabaya: Universitas Kristen Petra. Manajemen Perhotelan, 2015.

Poltak Lijan. Manajemen Sumber Daya Manusia. Cetakan Kesatu. Jakarta: Bumi Aksara.

Payman J. Simanjutak (2011). Manajemen Sumber Daya Manusia. Cetakan Kesatu. Bandung: Alfabeta, 2016.

Rumindor, Vico Wentri. Motivasi, Disiplin Kerja dan Kepeimpinan Terhadap Produktivitas Kerja Pada Badan Kepegawaian dan Diklat Daerah Minahasa Selatan: Jurnal Emba Vol. 1 No. 4 Desember, Hal 1042-1052, 2013.

Rivai dan Segala. Manajemen Sumber Daya Manusia. Bandung: Alfabeta, 2011

Sedarmayanti. Manajemen Sumber Daya Manusia Reformasi Birokrasi dan Manejemen Pegawai Negeri Sipil. Bandung: PT. Refika Aditama, 2015.

Sedarmayanti. Tata Kerja dan Produktivitas Kerja. CV. Mandar Maju, 2015.

Sugiyono. Metode Penelitian Kuantitatif, Kualitatif, Dan R\&D”. Bandung: Alfabeta, 2014.

Sugiyono. Statistika Untuk Penelitian. Bandung: Alfabeta, 2010.

Sutrisno Edy.Manajemen Sumber Daya Manusia. Cetakan Kesatu. Jakarta: Kencana, 2014.

Siswartono. Pengaruh Kompensasi, Motivasi Kerja Dan Kompensasi Terhadap

Produktivitas Kerja Pada PT. Dua Putra Utama Makmur Di Kabupaten Pati. Jurnal.

Semarang: Universitas Dian Nuswantoro Semarang, 2012.

Suwatno dan Donni. Manajemen Sumber Daya Manusia dalam Organisasi Publik

dan Bisnis.Bandung: Alfabeta, 2014.

Sondang, Siagian P. Manajemen Sumber Daya Manusia. Jakarta: Bumi Aksara, 2008.

Windy Aprilia. Pengaruh Motivasi Kerja Dan Kompensasi Terhadap Produktivitas

Kerja. Jurnal Manajemen Mutu. Juli 2012 No. 2, 2012. 